\title{
Genotipos de VPH y cambios citológicos cervico-uterino en pacientes de una consulta ginecológica privada del Estado Carabobo, Venezuela. Marzo-octubre de 2017
}

\author{
Monica Sequera ${ }^{\mathrm{a}, \mathrm{b}}$, Andrea Matamoros a, Mendoza-León María Joséa \\ a Universidad de Carabobo, Facultad de Ciencias de la Salud, Escuela de Ciencias Biomédica y Tecnológica, Departamento de Mirrobiología. ${ }^{\text {b }}$ \\ Licenciada En Bioanalisis, Magister en Medicina Veterinaria, Doctorado en Ciencias, monicasequera44@gmail.com \\ https://orcid.org/0000-0003-2852-8758 \\ DOI 10.22517/25395203.20781
}

\section{Resumen}

Introducción: La infección genital por el Virus de Papiloma Humano (VPH) se ha asociado con el cáncer cérvicouterino (CCE) al provocar la aparición de lesiones precursoras de cáncer en la zona de transformación de la unión escamocolumnar del cuello uterino. Existen más de 100 tipos de VPH, clasificados en bajo riesgo oncogénico (VPH-BR) y alto riesgo oncogénico (VPH-AR). Estudios reportan la infección por genotipos de alto riesgo en el 100\% de los CCE. En Venezuela, el 67,7\% de los CCE, se relacionan con el genotipo de VPHAR 16.

Objetivo: Detectar la presencia de VPH en pacientes con cambios citológicos cervicouterino.

Metodología: Se incluyeron 49 pacientes que presentaban cambios citológicos, se tomaron las muestras de la región endocervical y exocervical para la detección y genotipificación del virus mediante la técnica de Multiple PCR.

Resultados: Las alteraciones citológicas presentes fueron Células Escamosas Atípicas $(69,4 \%)$, Células Glandulares Atípicas $(4,1 \%)$, Lesión Escamosa Intraepitelial de Bajo Grado (16,3\%), y Lesión Escamosa Intraepitelial de Alto Grado (10,2\%). La detección molecular demostró que 16,3\% presentaba VPH, 62,5\% correspondían a VPH-AR, 25\% a VPH-BR, 12,5\% al genotipo 16 y no se detectó el genotipo 18 . Se reportó un solo caso de coinfección.

Conclusiones: A diferencia de otros estudios, no se encontró una relación estadísticamente significativa entre la presencia del virus y la aparición de cambios citológicos cervicouterino en esta población. No obstante, se detectaron genotipos de alto riesgo oncogénico, lo que puede traducirse en una mayor incidencia de cáncer cervicouterino a futuro.

Palabras clave: Genotipo, Papilomavirus, Citología, Epidemiología, Biología Molecular, Lesiones precancerosas.
HPV genotypes and cervical cytological changes in patients who attended a private gynecology appointment in the state of Carabobo, March-October 2017

\begin{abstract}
Introduction: Genital infection by the Human Papilloma Virus (HPV) has been associated with cervical cancer (CC) since it causes the appearance of precursor cancer lesions in the transformation area of the squamous-columnar junction of the cervix. There are more than 100 types of HPV that are classified as low oncogenic risk (LR-HPV) and high oncogenic risk (HR-HPV). Studies report that the infection by high-risk genotypes is present in $100 \%$ of CC. In Venezuela, $67.7 \%$ of $\mathrm{CC}$ is related to the HPV-16 genotype.
\end{abstract}

Objective: This study seeks to detect the presence of HPV in patients with cervical cytological cell changes.

Methodology: Forty-nine patients with cytological changes were studied. The endocervical and ectocervical areas were sampled to detect and genotype the virus by using the Multiplex PCR technique.

Results: The cytological alterations presented were: Atypical Squamous Cells (69.4\%), Atypical Glandular Cells (4.1\%), Low-grade Squamous Intraepithelial Lesion (16.3\%) and High-grade Squamous Intraepithelial Lesion (10.2\%). Besides, the general molecular detection showed that $16.3 \%$ had HPV, $62.5 \%$ of it corresponded to HR-HPV, $25 \%$ to LR-HPV, and $12.5 \%$ to genotype 16 . The genotype 18 was not detected, and only one co-infection case was reported.

Conclusions: Unlike other studies, a statistically significant relationship was not found between the virus presence and the appearance of cervical cytological cell changes in this population. However, genotypes with high oncogenic risk were detected, which may lead to a higher incidence of cervical cancer in the future.

Keys words: Genotype, Papillomavirus Infections, Cytology, Health Services Research, Molecular Biology, Precancerous Conditions. 


\section{Introducción}

El Virus de Papiloma Humano (VPH) es un virus de gran interés mundial por estar relacionado con el desarrollo de cáncer. Aproximadamente el $50 \%$ de las mujeres son infectadas en los primeros 5 años de haber iniciado las relaciones sexuales, siendo el principal factor de riesgo el cambio constante de pareja sexual. Se estima que en el $10 \%$ de la población infectada persistirá la infección por varios años, lo que podría ocasionar la transformación de las células y desarrollo de cáncer ${ }_{(1),(2)}$. El cáncer cérvicouterino (CCE) es el cuarto cáncer más frecuente entre las mujeres a nivel mundial, con un estimado de 527.624 casos nuevos y 265.672 muertes para el año $2012_{(3)}$. En Venezuela, con una población de 29.955.000 habitantes para el año 2014, se estiman 11.000 muertes producidas por cáncer, en las que $15,8 \%$ son causadas por $\mathrm{CCE}_{(4)}$.

Existen más de 100 tipos de VPH ${ }_{(5)}$, de los cuales 40 presentan tropismo por el área cutánea y área mucosa de la vía anogenital en ambos sexos, y pueden ser agrupados en VPH de bajo riesgo oncogénico (VPH-BR) 6, 11, 40, 42, 43, 44, 54, 61, 72 y 81 , entre los más frecuentes, y alto riesgo oncogénico (VPHAR) $16,18,31,33,34,35,39,45,51,52,56,58,59,66,68$, 70,73 y 82 . El considerarlos de bajo o alto riesgo oncogénico depende de la caracterización según la presencia en Lesiones Escamosas Intraepiteliales de Alto Grado (LEIAG), y carcinomas invasores $_{(6)}$. En Venezuela, 53,6\% de las LEIAG, y $67,7 \%$ de los CCE, se relacionan con el genotipo de VPHAR $16_{(7)}$. En relación a esto, el estudio realizado por Sánchez $z_{(8)}$ en una población de Málaga, España en el año 2012, y por Mijit et al. ${ }_{(9)}$, en Xinjiang, China en el año 2015, demostró que la infección por genotipos de alto riesgo está presente en $100 \%$ de los CCE, principalmente por el genotipo 16, mientras que $30 \%$ estuvo asociado al genotipo 18 . De igual modo, Krishnan et al. ${ }_{(10)}$, en un estudio realizado en el año 2015 en una población de Estados Unidos, señalan que el genotipo 16 y 18 son los más frecuentes.

La infección por VPH tiene un período de incubación de 6 semanas a 2 años, en la mayoría de la población este período latente o subclínico cura espontáneamente, pero un pequeño porcentaje puede perdurar y dar lugar a lesiones en la piel y $\operatorname{mucosas}_{(11)}$. La transformación de la célula hospedadora en una célula neoplásica con capacidad de infiltrar, se suele producir por la integración del genoma viral en el ADN de esta célula $_{(12)}$.

La relación existente entre la presencia de VPH y la aparición de algún cambio citológico se ha demostrado en diversas investigaciones, como en los estudios realizados en el año 2013 por Pérez et al. ${ }_{(13)}$, y en el año 2015 por Kolawole et $\mathrm{al}_{(14)}$, en una población de México y Nigeria, respectivamente, encontraron que la prevalencia de VPH-AR es alta, entre $95 \%$ y $100 \%$ en las pacientes con resultados anormales de citología. Sin embargo, la presencia del virus no es suficiente para promover el desarrollo de LEIAG y CCE ${ }_{(14)}$. En la transformación maligna intervienen otros factores como genotipo y carga viral, tabaquismo, multiparidad, hormonas, inmunodepresión, otras infecciones, nutrición y dieta, los cuales modulan el riesgo de progresión, pero no actúan con independencia del VPH. Wang et al. ${ }_{(15)}$, concluyeron que las interacciones pueden explicar por qué la alta frecuencia de la infección por VPH, no se relaciona con una alta frecuencia de CCE.

El VPH no se puede cultivar in vitro; por lo que la detección del virus y los distintos genotipos dependen estrictamente de análisis moleculares de la secuencia de $\mathrm{ADN}_{(16)}$. Las muestras celulares deben ser obtenidas del sitio anatómico, y fracasos en la detección del ADN del VPH no excluyen la infección en el paciente, como ocurre en casos con baja carga viral ${ }_{(17)}$. $\mathrm{Si}$ se detecta VPH-AR en una paciente con un cambio citológico, la presencia viral es un elemento que diferencia el tratamiento y seguimiento ${ }_{(18)}$. Por lo que la detección molecular permite mejor diagnóstico y manejo del tratamiento en los pacientes (19) ${ }^{\circ}$

Por tanto, en la siguiente investigación se evaluó la asociación de los genotipos de VPH, tipificados mediante la técnica de Reacción en Cadena de la Polimerasa (PCR) en muestras de hisopado de cuello uterino, con los cambios citológicos descritos en la citología cérvicouterina de pacientes que asistieron a la consulta de ginecología de un centro de salud privado del Estado Carabobo, en el período marzo-octubre 2017. Esto, con la finalidad de conocer los tipos virales circulantes en la población estudiada, lo que contribuiría a mejorar la data estadística, facilitando el desarrollo e implementación de programas de prevención y tratamiento de la enfermedad para disminuir la mortalidad asociada.

\section{Materiales y métodos}

\section{Pacientes}

El siguiente trabajo fue de tipo descriptivo y correlacional, no experimental y transeccional. La muestra estuvo conformada por 49 mujeres que asistieron a la consulta de ginecología de un centro de salud privado del Estado Carabobo, en el período marzo a octubre de 2017, con edades comprendidas entre 18 y 40 años, sexualmente activas. El médico seleccionó aquellas pacientes que reflejaban en la citología cambios citológicos en el cuello uterino, de acuerdo con el Sistema Bethesda 2001 (12), a las pacientes se les informó acerca del estudio en el que participaron y firmaron un consentimiento informado. 


\section{Toma de muestras}

El médico se encargó de la toma de la muestra mediante un raspado firme del endocervix y exocervix, sin producir sangrado con hisopo de algodón estéril, éste se colocó en un vial estéril y fue trasladado debidamente para ser preservado a $4{ }^{\circ} \mathrm{C}$, en el Laboratorio de Biología Molecular del Departamento de Microbiología, de la Escuela de Ciencias Biomédicas, Facultad de Ciencias de la Salud de la Universidad de Carabobo, donde fue procesado para extracción de ADN, amplificación y detección electroforética de VPH. Además de llenar la ficha epidemiológica de cada paciente, la cual suministraba datos de importancia para el estudio, como la edad, antecedentes de infección de transmisión sexual (ITS), el número de parejas sexuales y el cambio citológico presente, si se trataba de Células Escamosas Atípicas (ASC), Células Glandulares Atípicas (AGC), Lesión Intraepitelial Escamosa de Bajo Grado (LEIBG), Lesión intraepitelial Escamosa de Alto Grado (LEIAG).

\section{Extracción y Amplificación del ADN de VPH}

Se investigó la presencia de ADN viral del VPH y sus genotipos utilizando la técnica de PCR en las 49 muestras tomadas. Para la extracción del ADN se utilizó el kit RibospinTM vRD, siguiendo las instrucciones del fabricante ${ }_{(20)}$.

En un tubo de microcentrifuga de $1,5 \mathrm{~mL}$, se añadió $500 \mu \mathrm{L}$ de buffer "VL", y se introdujo el hisopo para que el buffer actuara sobre la muestra, luego se agitó en el vortex durante 3 segundos y se dejó reposar 10 minutos a temperatura ambiente. A continuación, se añadió $700 \mu \mathrm{L}$ de buffer de unión "RB1" y se mezcló en el vortex $3 \mathrm{seg}$. Se transfirió $750 \mu \mathrm{L}$ del contenido del tubo de microcentrifuga a una minicolumna. Se procedió a centrifugar a $17.217,14 \mathrm{~g}$ durante $30 \mathrm{seg}$. a temperatura ambiente, se descartó la solución que quedó en el fondo y se colocó la columna en el mismo tubo. Se Añadió 500 $\mu \mathrm{L}$ de tampón de lavado "RBW" a la columna y se centrifugó nuevamente a $17.217,14 \mathrm{~g}$ durante $30 \mathrm{seg}$. Se descartó la solución que quedó en el fondo y se colocó nuevamente la columna en el mismo tubo. Se Añadió $500 \mu \mathrm{L}$ de tampón de lavado B "RNW" a la columna y se centrifugó a 17.217,14 g durante $30 \mathrm{seg}$., se descartó la solución que quedó en el fondo y se colocó la columna en el mismo tubo, se centrifugó a $17.217,14 \mathrm{~g}$ durante $1 \mathrm{~min}$. a temperatura ambiente, para secar bien el etanol residual.

Se transfirió la columna a un nuevo tubo de microcentrifuga de $1,5 \mathrm{ml}$ libre de RNAsas y se agregó $60 \mu \mathrm{L}$ de agua libre de nucleasa directamente sobre la membrana. Se incubó durante 1 min. a temperatura ambiente y luego se centrifugó a 17.217,14 g durante $1 \mathrm{~min}$. Para la amplificación del ADN viral se utilizó la técnica de PCR múltiple con kit comercial SEEPLEXTM
HPV4 ACE Screening de Seegene, siguiendo el protocolo del fabricante $_{(21)}$. En primer lugar se preparó la PCR mastermix con $200 \mu \mathrm{L} 5 \mathrm{X}$ HPV4A ACE PM (primers o cebadores), 150 $\mu \mathrm{L} 8$-MOP Solution y $500 \mu \mathrm{L} 2 \mathrm{X}$ Multiplex Master Mix. Para la reacción se midieron $17 \mu \mathrm{L}$ de la PCR mastermix y se pasaron a tubos de PCR $0.2 \mathrm{ml}$, se añadieron $3 \mu \mathrm{L}$ del ADN de la muestra, para el control negativo se añadieron $3 \mu \mathrm{L}$ de HPV4A ACE NC y para el control positivo $3 \mu \mathrm{L}$ de HPV4A ACE PC en lugar de la muestra. Las amplificaciones se realizaron en un termociclador MiniCycler ${ }^{T M}$ de MJ Research INC, se inició el ciclo con la desnaturalización, calentando a $95^{\circ} \mathrm{C}$ por $15 \mathrm{~min}$, seguido de $94^{\circ} \mathrm{C}$ por $30 \mathrm{seg}$., $63^{\circ} \mathrm{C} 90 \mathrm{seg}$. para fijar los cebadores, seguido de $72^{\circ} \mathrm{C} 90 \mathrm{seg}$. para que actúe la taq-polimerasa, por 40 ciclos; por último, $72^{\circ} \mathrm{C}$ por $10 \mathrm{~min}$.

\section{Detección y genotipificación del VPH}

Los productos amplificados fueron analizados mediante electroforesis en gel de agarosa 1,5\%, conteniendo 0,8 $\mu 1$ de SYBR ${ }^{\circledR}$ Green I Nucleic Acid Gel Stain (SIGMA) a una concentración de 10000X DMSO y las corridas se realizaron utilizando una corriente eléctrica de 150 voltios por 30 minutos. Se visualizaron las bandas de ADN en un transiluminador de luz ultravioleta, la distancia recorrida por la banda de la muestra fue comparada con la distancia recorrida por las bandas del marcador de pares de base (1000 pb) para identificar el genotipo de VPH con base en el tamaño del producto amplificado.

\section{Análisis de Datos}

Para la demostración de la distribución de las variables y las asociaciones se realizaron análisis de Chi-cuadrado y se utilizaron los programas SPSS versión 18 y Prism 18 (GraphPad Software, Inc.). Un valor de $\mathrm{P}<0,05$ fue considerado estadísticamente significativo con un $95 \%$ de confianza.

\section{Resultados}

Este estudio fue realizado en 49 mujeres que asistieron a la consulta ginecológica de un centro de salud privado, con edades comprendidas entre 18 y 25 años, la edad promedio fue de 27 años, se obtuvieron muestras de hisopado vaginal de la región endocervical y exocervical de las pacientes. Como resultado hallamos que la mayor prevalencia de cambios citológicos $(51 \%)$ corresponden al grupo etario entre 1825 años, en donde en el 58,8\% presentó células escamosas atípicas (ASC) y representan el $60 \%$ de las pacientes con lesión intraepitelial de alto grado (LEIAG). Respecto a las pacientes con edades comprendidas entre 34-40 años, el $50 \%$ presentó lesión intraepitelial de bajo grado, sin embargo al asociar estas variables no se encontró relación estadísticamente significativa 
(Chi 2 test $P>0.05)$, entre la edad y la aparición de cambios citológicos (TABLA 1).

Tabla 1. Cambios citológicos encontrados en 34 pacientes que asistieron a una consulta ginecológica.

\begin{tabular}{l|lll|ll|ll|ll|ll|}
\hline $\begin{array}{l}\text { Grupo } \\
\text { etario }\end{array}$ & \multicolumn{2}{|l|}{$\mathrm{ASC}^{\mathrm{a}}$} & \multicolumn{2}{|l|}{$\mathrm{AGC}^{\mathrm{b}}$} & \multicolumn{2}{|l|}{ LEIBG $^{\mathrm{l}}$} & \multicolumn{2}{|l|}{ LEIAG $^{\mathrm{d}}$} & \multicolumn{2}{|l}{ Total } \\
\cline { 2 - 11 } & $\mathrm{n}$ & $\%$ & $\mathrm{n}$ & $\%$ & $\mathrm{n}$ & $\%$ & $\mathrm{n}$ & $\%$ & $\mathrm{n}$ & $\%$ \\
\hline $18-25$ & 20 & 58,8 & 0 & 0,0 & 2 & 25,0 & 3 & 60,0 & 25 & 51,0 \\
$26-33$ & 9 & 26,5 & 2 & 100,0 & 2 & 25,0 & 0 & 0,0 & 13 & 26,5 \\
$34-40$ & 24 & 14,7 & 0 & 0,0 & 4 & 50,0 & 2 & 40,0 & 11 & 22,4 \\
Total & 34 & 69,4 & 2 & 4,1 & 8 & 16,3 & 5 & 10,2 & 49 & 100 \\
\hline
\end{tabular}

\section{Detección de ADN Viral y su relación con cambios citológicos}

Las pacientes que asistieron a la consulta, bajo previo consentimiento informado, permitieron realizar la detección molecular mediante la técnica de Reacción en Cadena de la Polimerasa (PCR), en donde se logró realizar la detección de la presencia del Virus de Papiloma Humano en 16,3\% (n = 8/49) de las pacientes (Figura 1). Dicha detección viral, permitió realizar la correlación con los cambios citológicos presentes (Figura 2 A), observándose que el 62,5\% de las pacientes (n $=5 / 8$ ) presentó células escamosas atípicas (ASC), un 25\% (n = 2) presentó Lesión intraepitelial de alto grado (LEIAG), y un $12,5 \%(\mathrm{n}=1 / 8)$ presentó lesión intraepitelial de bajo grado (LEIBG), sin embargo al evaluar la relación entre los cambios citológicos con las pacientes que obtuvieron un resultado negativo para ADN viral (Figura 2 B), no se encontró relación estadísticamente significativa entre la presencia de VPH y la aparición de cambios citológicos.

Figura 1. Detección de ADN del virus de Papiloma Humano en pacientes que asistieron a consulta ginecológica.

\section{Detección ADN VPH}

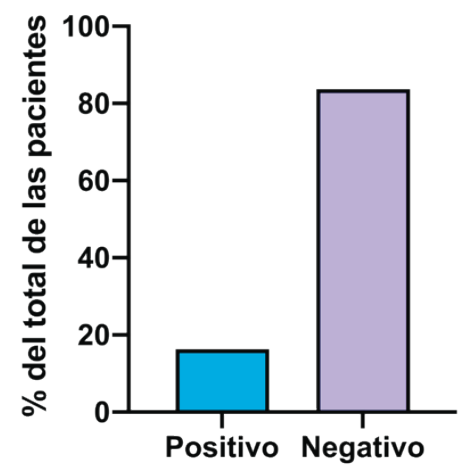

Del total de las 49 muestras de hisopados de mujeres en edades comprendidas entre 18 y 40 años, el $83,7 \%$ de las pacientes no presentó ADN viral $(n=41 / 49)$, mientras que se detectó el virus de VPH en el $16,3 \%$ de las pacientes $(n=8 / 49)$
Figura 2. Correlación entre pacientes con VPH y la presencia de cambios citológicos.

\section{A}

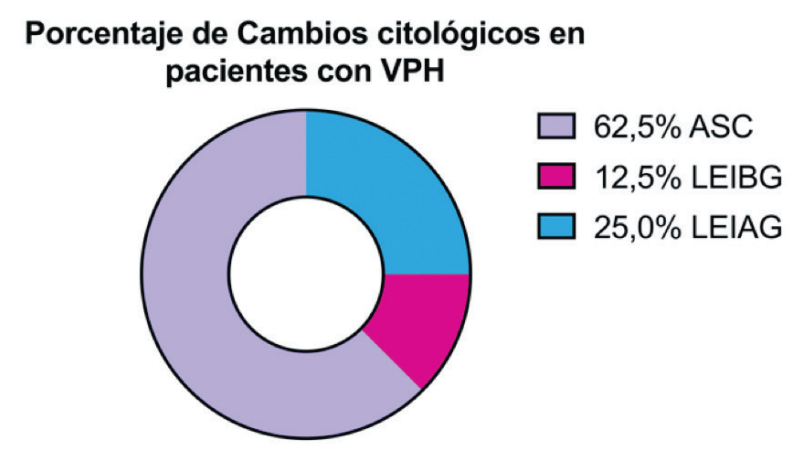

B

\section{Porcentaje de Cambios citológicos en pacientes nagativos para VPH}

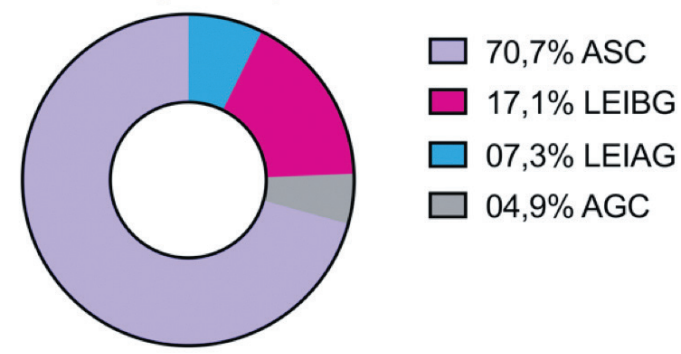

A) De las mujeres diagnósticadas con VPH, los resultados de la citología reveló un mayor porcentaje de cambios citológicos de ASC 62,5\% ( $\mathrm{n}=5 / 8)$, LEIBG 12,5\% $(\mathrm{n}=1 / 8)$, LEIAG $25 \%(\mathrm{n}=2 / 8)$ y no se detectó ADN viral en pacientes con AGC. B) De las pacientes sin presencia viral, la mayoría de las pacientes presentó ASC en un 70,7\% ( $\mathrm{n}=29 / 41)$, LEIBG $17,1 \%(\mathrm{n}=7 / 41)$, LEIAG $7,3 \%(\mathrm{n}=3 / 41)$ y ACG $4,9 \%(\mathrm{n}=$ $2 / 41$ ). No hubo diferencias significativas entre la presencia de VPH y los cambios citológicos ASC $=$ Células Escamosas Atípicas $(P=0,644)$, AGC $=$ Células Glandulares Atípicas $(P=0,524)$, LEIBG $=$ Lesión Intraepitelial de Bajo Grado $(P=0,749)$, LEIAG $=$ Lesión Intraepitelial de Alto Grado $(P$ $=0,131)$, Análisis realizado mediante prueba del de Pearson, NS, no significativo $(\mathrm{P}>0.05), 95 \%$ de confianza.

La genotipificación del virus (Figura 3), demostró que el $62,5 \%$ de las pacientes presentaron positividad para los genotipos de eran para el gen común de alto riesgo (HRC), el cual abarca los genotipo 31, 33, 35, 39, 45, 51, 52, 56, 58, $59,66,68,26,53,69,73,82$, mientras que $25 \%$ para el gen común de bajo riesgo, que incluye los genotipos 6 y 11, $12.5 \%$ para el genotipo 16, en las pacientes evaluadas no se detectó el genotipo 18. A pesar de no encontrar estadísticas significativas 
entre el genotipo de VPH y el cambio citológico, de las dos pacientes con lesión intraepitelial de alto grado presentaron el genotipo 6/11 y el gen común de alto riesgo, mientras que la paciente con lesión intraepitelial de bajo grado presentó el gen común de alto riesgo (12,5\%), y las pacientes con células escamosas atípicas presentaron los genotipos de alto riesgo en un mayor porcentaje $(37,5 \%)$.

Figura 3. Correlación entre pacientes con cambios citológicos y la presencia de distribución de los genotipos de VPH.

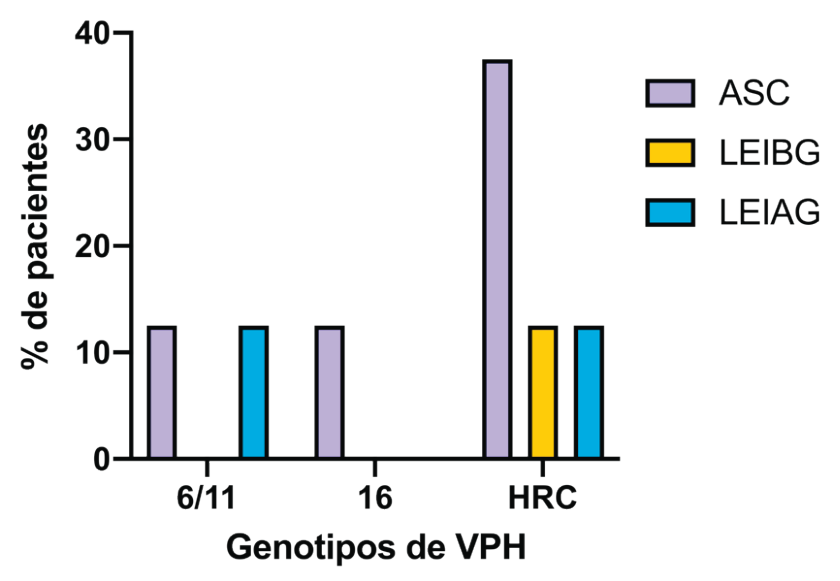

El mayor porcentaje de genotipos detectados se detectó en las padientes que presentaron células escamosas atípicas ASC $62,5 \%(\mathrm{n}=5 / 8)$ ns $P=0.792$, seguido de las pacientes con lesión intraepitelial de alto grado LEIAG $25 \%(\mathrm{n}=2 / 8) P=$ 0,885 , y Lesión intraepitelial de bajo grado LEIBG 12,5\% (n $=1 / 8) P=0.215$. Análisis realizado mediante prueba del de Pearson, NS, no significativo $(\mathrm{P}>0.05), 95 \%$ de confianza. Genotipos de VPH 6 y 11, 16, y alto riesgo HRC, que abarcan los genotipos $(31,33,35,39,45,51,52,56,58,59,66,68,26$, $53,69,73,82)$.

Genotipos de alto riesgo se distribuyen entre los distintos cambios citológicos y los distintos genotipos de VPH 6/11, 16 y de alto riesgo se encuentran en mayor proporción en pacientes con Células escamosas atípicas

\section{Correlación entre los genotipos de VPH con la edad y número de parejas sexuales}

Para evaluar la correlación existente entre los genotipos de VPH y la presencia de lesiones epiteliales de alto grado como factor de riesgo para la progresión de cáncer cérvico uterino, se detectó que las pacientes jóvenes de 18 a 25 años presentaron el $50 \%$ de los genotipos evaluados, mientras que el otro $50 \%$ correspondió a genotipos de alto riesgo (Figura 4).
Figura 4. Correlación entre edad de las pacientes con cambios citológicos y genotipos de VPH.

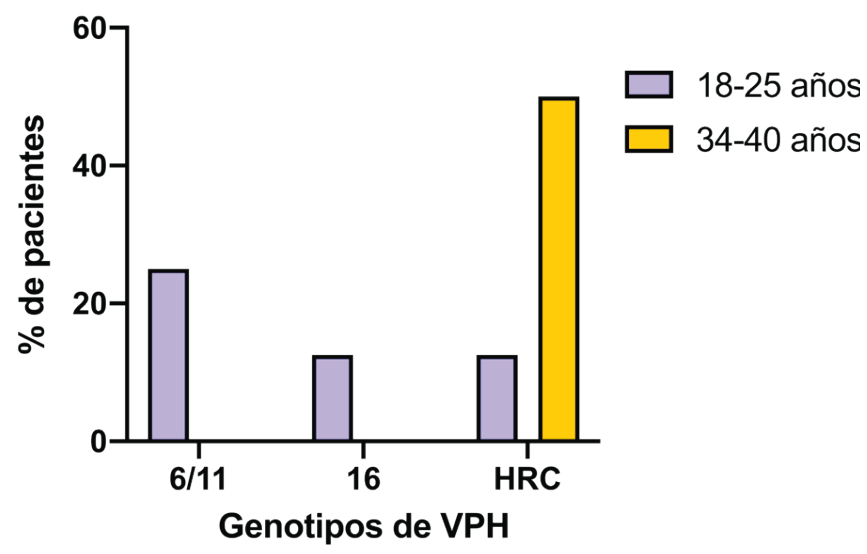

Al evaluar la edad como factor de riesgo, se pudo observar que las pacientes más jóvenes presentan una distribución del $50 \%$ de los distintos genotipos, mientras que el gen común de alto riesgo predominó en las pacientes de 24-40 años, no detectandose la presencia de VPH en las pacientes con edades de 26-33 años. Análisis realizado mediante prueba del de Pearson, NS, no significativo $(\mathrm{P}>0.05), 95 \%$ de confianza. Genotipos de VPH 6 y 11, 16, y alto riesgo HRC, que abarcan los genotipos $(31,33,35,39,45,51,52,56,58,59,66,68,26$, $53,69,73,82)$.

Al evaluar las interacciones entre el número de parejas sexuales y el contagio del virus en las pacientes, no se encontró relación estadísticamente significativa, se observa que $85,7 \%$ de las pacientes ha tenido entre 1 y 4 parejas sexuales, y $16,7 \%$ de ellas presentaba VPH (TABLA 2).

Tabla 2. Relación número de parejas sexuales y presencia de VPH.

\begin{tabular}{|c|c|c|c|}
\hline Número de Parejas & ADN & VPH & \\
\hline Sexuales & $\begin{array}{l}\text { Positivo } \\
\text { n \% }\end{array}$ & $\begin{array}{l}\text { Negativo } \\
\text { n \% }\end{array}$ & $\begin{array}{l}\text { Total } \\
\text { n \% }\end{array}$ \\
\hline $1-4$ & 716,7 & 3575,0 & 485,7 \\
\hline $5-9$ & $\begin{array}{ll}0 & 0,0\end{array}$ & 4100,0 & 48,2 \\
\hline $10-15$ & 133,3 & 266,7 & 36,1 \\
\hline Total & 816,3 & 4183,7 & 49100,0 \\
\hline
\end{tabular}

Prueba del chi ${ }^{2}$ de Pearson: ${ }^{*} \mathrm{p}>0,05$ estadísticamente no significativo 


\section{VPH como la enfermedad de transmisión sexual entre las pacientes que asistieron a la consulta ginecológica}

Además de la búsqueda en la identificación de los genotipos predominantes en las pacientes que asistieron a la consulta ginecológica, fue relevante evaluar el historial clínico de cada una de las pacientes e identificar el diagnóstico de otra infección de transmisión sexual (Tabla 3), lo que nos permitió observar que el 8,2\% presentó algún tipo de ITS, y que dentro de este porcentaje solo el $25 \%$, correspondiente a 1 paciente. Además, se pudo observar que el mayor porcentaje de pacientes que no se les detectó presencia de VPH, solamente 3 de las 38 pacientes presentaron un agente infeccioso diferente al VPH.

Tabla 3. Relación entre la presencia de VPH y otra infección de transmisión sexual en las pacientes que asistieron a la consulta de ginecología de un centro de salud privado del Estado Carabobo marzo-octubre 2015.

\begin{tabular}{lcll}
\hline $\begin{array}{l}\text { Presencia de otro } \\
\text { agente infeccioso }\end{array}$ & ADN & VPH & \\
\cline { 2 - 4 } & Positivo & Negativo & Total \\
& $\mathbf{n} \%$ & n \% & n \% $\mathbf{p}^{*}$ \\
\hline $\mathrm{Si}$ & 125,0 & 375,0 & $48,20,240$ \\
No & 715,6 & 3884,4 & 4591,8 \\
Total & 816,3 & 4183,7 & 49100,0 \\
\hline
\end{tabular}

Prueba del chi ${ }^{2}$ de Pearson: *p>0,05 estadísticamente no significativo

\section{Discusión}

Las alteraciones citológicas presentes fueron según porcentaje de frecuencia, células escamosas atípicas (ASC), células glandulares atípicas (AGC), lesión escamosa intraepitelial de bajo grado (LEIBG) y lesión escamosa intraepitelial de alto grado (LEIAG). La detección molecular demostró que 16,3\% de la muestra presentaba Virus de Papiloma Humano, 62,5\% correspondían al gen común de alto riesgo $(31,33,35,39,45$, $51,52,56,58,59,66,68,26,53,69,73,82), 25 \%$ a genotipos de bajo riesgo 6/11, 12,5\% al genotipo 16 y no se detectó el genotipo 18

La presencia de ASC fue la alteración citológica predominante, esto se relaciona con el estudio realizado por González et al. ${ }_{(22)}$, en la ciudad de Bogotá, en el que las ASC fueron la anormalidad citológica más frecuente en todos los grupos etarios, pero contrasta con otros estudios realizados por Mendoza et al. ${ }_{(23)}$ (Tuluá, Colombia), Pérez et al. ${ }_{(13)}$ (México), y Rojas et al. (24) (Barquisimeto, Venezuela) en los que predominaron las LEIBG y LEIAG, por lo que la prevalencia de anormalidades citológicas varía según el tipo de población en estudio y los factores de riesgos inherentes a la misma.

La detección molecular mediante la técnica de PCR, demostró que el porcentaje de positividad fue inferior al reflejado en investigaciones cuya población de estudio correspondía a mujeres venezolanas, tal es el caso de López et al. ${ }_{(25)}$ (Mérida), Salazar et al. (26) (Cumaná) y Mena et al. (27) (Valencia).

De igual modo, en estudios internacionales como el de Pérez et al. ${ }^{13)}$ (México), Assoumou et al. ${ }_{(28)}$ (Gabón), Jariene et al. (29) (Lituania) y Kolawole et al. ${ }_{(14)}$ (Nigeria), se evidencia que la presencia de VPH en pacientes con cambios citológicos variaba entre $53,4 \%$ y $100 \%$, en esta investigación los pacientes que presentaban lesiones, no necesariamente eran producidas por el VPH, puede deberse en parte, a que la mayoría de las pacientes estudiadas presentaban ASC, alteración citológica que puede ser ocasionada por otras razones como: irritación, infección vaginal por hongo; algunos tumores como los pólipos o quistes benignos; así mismo por cambios hormonales, y no exclusivamente debido a la presencia de $\mathrm{VPH}_{(30),(31)}$, esto se demuestra en un estudio realizado por Baptista et al. ${ }_{(32)}$ en el que señala que la presencia de inflamación e infecciones moderadas o graves independientes del VPH se asocia con un mayor riesgo de anomalías citológicas cervicales.

En cuanto a la genotipificación del virus, aunque no fue posible detectar específicamente cuál genotipo presentaban las pacientes positivas al HRC, debido a que el kit de detección molecular utilizado determinaba un gen que presentan en común este grupo de genotipos de VPH-AR, se relacionan con un estudio realizado por Rivas et al. ${ }_{(33)}$ en la ciudad de Caracas, donde de igual manera encontraron predominio de VPH-AR diferentes al genotipo 16 y 18; no obstante, otros estudios nacionales muestran una mayor prevalencia de genotipos de bajo riesgo como indican los estudios de Mena et al. ${ }_{(27)}$, Sanoja et al ${ }_{\text {(34) }}$ y de Pulido et al. ${ }_{(35)}$.

De las pacientes que presentaban LEIBG y LEIAG en este estudio solo 3 presentaron lesiones para VPH (2 VPH HR y 1 VPH 6/11), esto fue inferior al reflejado en otros estudios ${ }_{(26)}$ (36), en donde detectaron que entre $50 \%$ y $98 \%$ de pacientes con lesión escamosa intraepitelial (LEI) presentaban VPH-AR, en algunos casos la detección molecular del virus se dificulta debido a características propias de la muestra, como baja carga viral o la presencia de interferencias, por ende la obtención de falsos negativos en los resultados. En diversos estudios se evidencia la presencia de VPH en un alto porcentaje de CCE (7), (8) $\mathrm{y}$ demuestran la relación que existe entre la presencia del virus y la aparición de alteraciones del parénquima del cuello uterino, que pueden progresar a CCE.

La evolución de las LEIBG y LEIAG es variable, la sola presencia del ADN viral no es indicativa de una transformación maligna, puesto que son otros factores de riesgo las que apoyan la malignidad ${ }_{(15),(37)}$. De las 5 pacientes con LEIAG, solo una presentaba VPH, además de ser la única paciente en el estudio 
en quien se pudo evidenciar coinfección, siendo positiva para el HRC y genotipo 16.

En diversos estudios, como el de Salazar et al. ${ }_{(38)}($ Estados Unidos), señalan que $32,2 \%$ de las pacientes con infección por VPH y LEI presentaban coinfección. En este sentido, Tran et al. ${ }_{(39)}$ (Vietnam), reportan que $20 \%$ de las pacientes a las que se les detectó VPH presentaban coinfección con genotipos de alto riesgo, ellos afirman que las infecciones por múltiples genotipos de VPH son comunes, y que está asociada con un mayor riesgo de CCE.

Es importante resaltar que existe la presencia de genotipos de alto riesgo oncogénico en esta población, lo que tiene importancia epidemiológica local, ya que puede traducirse en una mayor incidencia de CCE a futuro. El detectar la presencia del HRC, del genotipo 16 y del 6/11, en las pacientes entre 1825 años indica que debe seguirse el tratamiento y evolución de estas pacientes y se relaciona con diversos estudios en los que se describe la presencia de genotipos de alto y bajo riesgo oncogénico en las pacientes menores de 25 años La presencia de únicamente el HRC en pacientes (25), (34), (35) años, concuerda con la historia natural del virus, en la que contagio ocurre a edades tempranas y permanece en estado de latencia durante meses o años ${ }_{(41) \text { y (42) }}$.

En cuanto a la relación que existe entre el número de parejas sexuales y el contagio del virus, los resultados obtenidos contrastan con los señalados en el estudio realizado por Puente et al. (40) en adolescentes, en donde $52,5 \%$ de las pacientes que manifestaron haber tenido 2 parejas sexuales en los últimos 6 meses presentaban VPH, y por el estudio realizado por Rodriguez et al. ${ }_{(41)}$, quienes describieron que 9 de cada 10 mujeres que tuvieron 3 o más compañeros sexuales presentaban VPH, por lo que el riesgo de adquisición del virus está relacionado con el inicio temprano de las relaciones sexuales y con tener diferentes parejas sexuales ${ }_{(2)}$.

Para la paciente que presentó ITS e infección por VPH, el cambio citológico asociado era LEIBG, fue positiva para el HRC y en los antecedentes de ITS manifestó presentar herpes (VHS). Un estudio realizado por Atencio et al. ${ }_{(43)}$, señala que las presencias de ambos agentes virales inducen la aparición de LEIBG, y Skeate et al. (44), en su estudio demuestra que la infección por VHS provoca una mayor susceptibilidad a la infección por VPH, y que es un cofactor responsable de las alteraciones del parénquima del cuello uterino relacionadas con el desarrollo de CCE.

La frecuencia y la genotipificación del VPH obtenidos en la población estudiada, aún cuando no son extrapolables debido a lo pequeño de la muestra, y a las variaciones en los cambios citológicos, tienen relevancia dado la importancia del problema ya que proporciona información que permite el diseño de acciones permanentes de prevención primaria y secundaria del CCE en la población femenina.

Se recomienda para investigaciones futuras ampliar la muestra de estudio, así como evaluar otros factores de riesgo que pueden incidir en la infección por VPH, y el desarrollo de CCE, como la terapia hormonal, tabaquismo, uso de métodos anticonceptivos y paridad. De igual forma, sería de interés epidemiológico detectar específicamente los genotipos de alto riesgo diferentes al 16 y 18 , lo cual no pudo realizarse en esta investigación. 


\section{Referencias}

1. Pfister H. Prophylaxis and early Detection of HPVrelated Neoplasia [Internet]. Germany: S. Karger AG; 2012 [consultado 2016 Ene 24]. Disponible en: http://goo.gl/vrFni0

2. Bhatia N, Lynde C, Vender R, Bourcier M. Understanding genital warts: epidemiology, pathogenesis, and burden of disease of human papillomavirus. J Cutan Med Surg [Internet] 2013 [consultado 2016 Abr 01]; 17 (2): p. 47-54. Disponible en: http://goo.gl/fOfdLD

3. Bruni L, Barrionuevo L, Albero G, Aldea M, Serrano B, Valencia S, et al. Human Papillomavirus and Related Diseases in the World. Summary Report. ICO HPV Information Centre [Internet]2015 [consultado 2016 Abr 29]. Disponible en: http://goo.gl/YHpP3m

4. Organización Mundial de la Salud. Perfiles oncológicos de los países. 2014; 3-6. Disponible en: http://goo.gl/PqBNMr

5. Gélinas C, Michaud C, Bérubé M, Brien L, Trochet C, Brassard Y. Soins infirmiers: médecine-chirurgie. Bruxelles: Chenelière Éducation inc [Internet]2011 [consultado 2016 Feb 03]. Disponible en: https://goo.gl/O8Y8CE

6. Brebi M, Ili G, López M, García M, Melo A, Montenegro $\mathrm{H}$, et al. Detección y tipificación de virus papiloma humano en adenocarcinoma de cuello uterino mediante reverse lineblot, Región de La Araucanía, Chile. Rev. Méd. Chile [Internet] 2009 [consultado 2016 Feb 03]; 137: 377-382. Disponible en: http://goo.gl/YBDpnm

7. ICO Information Centre on HPV and Cancer. Venezuela Human Papillomavirus and Related Cancers, Fact Sheet 2016. [consultado2016May01].Disponibleen:http://goo.gl/GkjHQW

8. Sanchez E. Infección del virus papiloma humano y cáncer de cuello uterino: distribución de Genotipos en mujeres conizadas por lesión escamosa intraepitelial de alto grado (CIN 2-3) y análisis de los cofactores de cáncer de cérvix en málaga [Tesis Doctoral]. España, Universidad de Malaga, 2012. Disponible en: http://goo.gl/5FHZlY

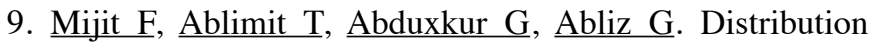
of human papillomavirus (HPV) genotypes detected by routine pap smear in Uyghur-Muslim womenfrom Karasay Township Hotan (Xinjiang, China). J. Med. Virol. [Internet] 2015 [consultado 2015 Abr 19]; 87 (11): 1960-1965. Disponible en: http://goo.gl/ttFBA4

10. Krishnan K, Thomas A. Correlation of cervical citology with high-risk HPV molecular diagnosis, genotypes, and Histopathology-A four year study from the UAE. Diagnostic Cytopathology. [Internet] 2015 [consultado 2015 Feb 05]; 44 (2): 91-97. Disponible en: http://goo.gl/Ps2qS4

11. Quintás L, Garcia P. Condilomas Genitales . Hospital Universitario Lucus Augusti. 2013 [consultado 2016 Feb 11]. Disponible en: http://goo.gl/57BW4C

12. Lacruz C,Fariña J.Citología ginecológica: De Papanicolaou a Bethesda. Madrid: Editorial complutense. [Internet] 2003 [consultado 2016 Ene 27] Disponible en: http://goo.gl/k6xn2y

13. Pérez A, Velázquez J, Cintora J, Herrera T, De la Torre F, Barriga F, et al. Genotipificación del Virus de Papiloma Humano de Alto Riesgo (VPH-AR) mediante PCR en pacientes de 25 a 34 años de edad con resultado de citología anormal. Archivos Médicos de Actualización en Tracto Genital Inferior. [Internet] 2013 [consultado 2016 Ene 27]; 9 (7): 43-50. Disponible en: http://goo.gl/Z7gVgc

14. Kolawole O, Ogah J, Alabi O, Suleiman M, Amuda O, Kolawole F. Utilization of Human Papillomavirus DNA Detection for Cervical Cancer Screening in Women Presenting With Abnormal Cytology in Lokoja, Nigeria. Jundishapur Journal of Microbiology. [Internet] 2015 [consultado 2015 Feb 05]; 8 (10). Disponible en: http://goo.gl/9m3rb8

15. Wang S, Zuna R, Wentzensen N, Dunn S, Sherman M, Gold $\mathrm{M}$, et al. Human papillomavirus (HPV) cofactors by disease progression and HPV types in the Study to Understand Cervical CancerEarly Endpoints and Determinants (SUCCEED). Cancer Epidemiol Biomarkers. [Internet] 2009 [consultado $2016 \mathrm{Feb}$ 05]; 18 (1):113-120. Disponible en: http://goo.gl/uDKW2o

16. De Ruiz P, Ponce L, Ávila M. Cáncer cervicouterino: Diagnóstico, prevención y control. México D.F: Elsevier Saunders. [Internet] 2005 [consultado 2016 Ene 24]. Disponible en: http://goo.gl/b4tu15

17. World Health Organization. Human papillomavirus laboratory manual. WHO/IVB. [Internet] 2010 [consultado 2016 Ene 24]. Disponible en: http://goo.gl/zIdTOA

18. Carreras R, Xercavins J, Checa MA. Virus del papiloma humano y cáncer de cuello de útero. Buenos Aires, Madrid: Ed. Médica Panamericana. [Internet] 2007 [consultado 2016 Feb 02]. Disponible en: https://goo.gl/jIQL8i

19. Arney A, Bennett k. Molecular Diagnostics of Human Papillomavirus. LABMEDICINE. [Internet] 2010 [consultado 2016 Ene 11]; 41(9). Disponible en: http://goo.gl/QHGnXl 


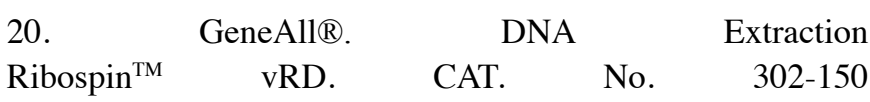

\section{Seegene. SEEPLEX ${ }^{\circledR}$ HPV4 ACE Screening.}

22. González M, Murillo R, Osorio E, Gamboa O, Ardila J. Prevalencia de anormalidades citológicas e histológicas de cuello uterino en un grupo de mujeres en Bogotá, Colombia. Rev. Colomb.Cancerol. [Internet] 2010 [consultado 2016 Abr 10]; 14 (1):22-28. Disponible en: http://goo.gl/zgfqKG

23. Mendoza L, Pedroza M, Micolta H, Ramírez A, Cáceres R, López D et al. Prevalencia de lesiones de bajo y alto grado de cuello uterino en una ciudad colombiana. Rev. Chil. Obstet. Ginecol. [Internet] 2012 [consultado 2016 Abr 10]; 77 (2):129136. Disponible en: http://goo.gl/wvI2Oh

24. Rojas J, Gutiérrez M, Rodríguez O, Galíndez J, Vergara C. Hallazgos citológicos asociados a patología cervical maligna Comunidad de Veragacha. Barquisimeto, Lara. Revista de Enfermería y otras Ciencias de la Salud. [Internet] 2013 [consultado 2016 Abr 10]; 6 (1): p. 39-46. Disponible en: http://goo.gl/bes5dN

25. López de M, Ferraro G, Quintero M, Gómez C, Puig Juan, Toro M. Infección por virus papiloma humano en pacientes con células escamosas atípicas de un programa de pesquisa de cáncer cervical. Rev. Obstet. Ginecol. Venez. [Internet] 2012 [consultado 2016 Abr 10]: 72 (1):p.19-27. Disponible en: http://goo.gl/XdkKgS

26. Salazar E. Detección del virus de papiloma humano en pacientes con lesiones intraepiteliales escamosas de cuello uterino. Rev. Obstet. Ginecol. Venez. [Internet] 2007 [consultado 2016 Abr 10]; p. 67 (1):47-54. Disponible en: http://goo.gl/dZSBgV

27. Mena O, Herrera A, Pérez Y, Colmenares O, Valera R. Infección múltiple por genotipos del Virus de Papiloma Humano en pacientes que acuden a consulta privada del Municipio Naguanagua [Salus]. [Internet] 2015 [consultado 2016 Abr 12]; 19 (3):p.14-19. Disponible en: http://goo.gl/ $\mathrm{Z} 8 \mathrm{n} 7 \mathrm{gp}$

28. Assoumou Z, , Mabika M, Ogoula N, Mzibri E, Khattabi $\underline{A}$, et al. Human papillomavirus genotypes distribution among Gabonese women with normal cytology and cervical abnormalities. Infect Agent Cancer. [Internet] 2016 [consultado 2016 Abr 19]; 11:2. Disponible en: http://goo.gl/Xhqs2X

29. Jarienė k, Vaitkienė D, Bartusevičius A, Tvarijonavičienè E, Minkauskienè M, Nadišauskienè R, et al. Prevalence of human papillomavirus types 16,18 , and 45 in women with cervical intraepithelial changes: associations with colposcopic and histological findings. Medicina (Kaunas) [Internet] 2012 [consultado 2016 Abr 10]; 48 (1):p.22-30. Disponible en: http://goo.gl/Bzi7vC

30. Palaoro L, Rocher A. Atypical Squamous Cells of Undetermined Significance: A subjective citodiagnosis . Acta bioquím. clín. latinoam. [Internet] 2007 [consultado 2016 Abr 10]; 41 (4):p. 511-517. Disponible en: http://goo.gl/UL6Sri

31. Instituto Nacional del Cáncer. Significado de los cambios en el cuello uterino Guía para la salud de la mujer. U.S. Department Of Health And Human Services. [Internet] 2007 [consultado 2016 Abr 10]. Disponible en: http://goo.gl/cMxggQ

32. Baptista V, Lima J, Pinto C, Saldanha C, Beires J, Martinez J, et al. Bacterial vaginosis, aerobic vaginitis, vaginal inflammation and major Pap smear abnormalities. Clin. Microbiol Infect. [Internet] 2016 [consultado 2014 Abr 18]; 35 (4):p. 657-664. Disponible en: http://goo.gl/9X14da

33. Rivas E, Verlezza S, Flores M. Distribución genotipoespecífico del virus papiloma humano entre hombres y mujeres de Caracas, Venezuela. Rev. Obstet. Ginecol. Venez. [Internet] 2012 [consultado 2014 Abr 10]; 72 (3): p. 171-176. Disponible en: http://goo.gl/GK5Ve6

34. Sanoja M. Detección y tipificación del virus del papiloma humano mediante reacción en cadena de polimerasa, en muestras cervicales de estudiantes, Universidad de Carabobo, Venezuela.Rev.Comunidady Salud.[Internet] 2013 [consultado 2014 Abr 10]; 11 (2):1-10. Disponible en: http://goo.gl/bfeTYc

35. Pulido A, Angulo A, Ávila M, Cavazza M, Crespo L, Vásquez W et al. Infección por el Virus de Papiloma Humano (VPH) en mujeres: Características epidemiológicas, clínicas y patológicas. Dermatol Venez. [Internet] 2012 [consultado 2014 Abr 10]; 49 (3): p. 3-4. Disponible en: http://goo.gl/HRqNB6

36. Posso A, Rangel M, Marchán N, González M. Lesión intraepitelial cervical en adolescentes. Rev. Obste.t Ginecol Venez. [Internet]2014 [consultado 2014 Abr 18]; 74 (3):p. 193-202. Disponible en: http://goo.gl/DDF00f

37. Sellors J, Sankaranarayanan R. La colposcopia y el tratamiento de la neoplasia intraepitelial cervical: Manual para principiantes. Lyon, France: Centro Internacional de Investigaciones sobre el Cáncer. [Internet]2003[consultado 2014 Abr 18]. Disponible en: http://goo.gl/VWpM6i

38. Salazar K, Zhou H, Xu J, Peterson L, Schwartz M, Mody, et al. Multiple Human Papilloma Virus Infections and Their Impact on the Development of High-Risk Cervical Lesions. 
Acta Cytologica. [Internet] 2015 [consultado 2016 Abr 26]; 59:p. 391-398. Disponible en: http://goo.gl/MXrsN6

39. Tran L, Tran L, Bul T, Le D, Nyitray A, Markham C, et al. Risk factors for high-risk and multi-type Human Papillomavirus infections among women in $\mathrm{Ho}$ Chi Minh City, Vietnam: a cross-sectional study. BMC Women's Health. [Internet] 2015 [consultado 2016 Abr 26]; 15:p.16. Disponible en: http://goo.gl/98tpP3

40. Puente M, Haber M, Losada A, Salas S. Adolescentes e infección por virus del papiloma humano. MEDISAN. [Internet] 2014 [consultado 2014 Abr 19]; 18 (6):p.769-775. Disponible en: http://goo.gl/1f5om6

41. Rodríguez D, Pérez J, Sarduy M. Infección por el virus del papiloma humano en mujeres de edad mediana y factores asociados. Rev. Cubana. Obstet. Ginecol. [Internet] 2014 [consultado 2016 Abr 19]; 40 (2):p.218-232. Disponible en: http://goo.gl/TkSGtr

42. Arenas R, Henríquez D, González M. Cáncer de cuello uterino en mujeres menores de 35 años y mayores de 60 años.Rev. Obstet. Ginecol. Venez. [Internet] 2011 [consultado 2016 May 30]; 71 (4): p. 252-264. Disponible en: http://goo.gl/6wQko6

43. Atencio R, Bracho A, Porto L, Callejas D, Gotera J, Pirela $\mathrm{N}$, et al. Determinación del virus papiloma humano y virus herpes simple y su posible relación con la presencia y tipo de lesiones preinvasivas del cuello uterino. Kasmera. [Internet] 2013 [consultado 2016 Abr 27]; 41 (2):p. 145-153. Disponible en: http://goo.gl/xASx4R

44. Skeate J, Porras T, Woodham A, Jang J, Taylor J, Brand $\mathrm{H}$, et al. Herpes simplex virus downregulation of secretory leukocyte protease inhibitor enhances human papillomavirus type 16 infection. J. Gen. Viro. [Internet] 2016 [consultado 2016 Abr 27]; 97 (2):p.422-434. Disponible en: http://goo.gl/ jyhkMa 